\title{
Analogies as Tools for Meaning Making in Elementary Science Education: How Do They Work in Classroom Settings?
}

\author{
Maria Teresa Guerra-Ramos \\ Centro de Investigación y de Estudios Avanzados Unidad Monterrey, Nuevo León, MEXICO
}

Received 18 March 2010; accepted 23 November 2010

In this paper there is a critical overview of the role of analogies as tools for meaning making in science education, their advantages and disadvantages. Two empirical studies on the use of analogies in primary classrooms are discussed and analysed. In the first study, the 'string circuit' analogy was used in the teaching of electric circuits with students aged 8-9. In the second study, the 'making a cake' analogy was introduced within the study of photosynthesis with students aged 10-11. Outcomes of both studies are scrutinised to assess the effectiveness of analogies as tools for meaning making. How the analogies are presented, their contexts, and how much students are involved in mapping the analogical relations appear to be determinant. This strongly suggests that research and pedagogical practice should shift from determining the effectiveness of analogy in cognitive transfer, from analogue to target domains, towards the recognition of its role in generating engagement in developing meaningful explanations through discourse. Finally, most salient aspects of the use of analogies are considered for contexts in which they are used to promote understanding of scientific ideas. Analogy can play and important role in that task if it is seen as a resource to promote understanding and meaning making but its strengths and limitations are not ignored.

Keywords: Analogy, Primary Education, Classroom Settings, Research Analysis

\section{INTRODUCTION}

Analogies, metaphors and models are common devices in everyday experience, spoken and written communication when trying to make familiar the unfamiliar. Very often, they are collectively considered to be analogies because of their potential to compare one object or situation to another, and in that process, transfer either details, relational information or both (Duit, 1991). Not surprisingly, the capacity to establish analogies among different objects is regarded as a relevant feature of human intelligence (Eysenck, 2000).

Correspondence to: Maria Teresa Guerra-Ramos, Ph.D of Science Education, Centro de Investigación y de Estudios Avanzados del IPN-Unidad Monterrey, Via del Conocimiento 201, PIIT, Apodaca, Nuevo León, C. P. 66600, MEXICO E-mail:tguerra@cinvestav.mx
The important role of models and analogies as part of scientific theories and explanations has been widely discussed in philosophical literature (e. g. Harré, 1972). Historically, according to Nagel (1971), there are plenty of examples about the influence of analogies upon the formation of theoretical ideas; cases in which analogy served as guide for setting up the fundamental assumptions of a theory, as well as a source of suggestions for extending the range of their application. It has also been argued that analogies and models are not only aids to discovery, insight and explanation, but an essential part of theories and indispensable and inevitable tools for scientific progress' (Oppenheimer, 1956; quoted in Glynn, 1991).

Given their importance as intellectual tools in science and useful devices for communication, it is not strange that analogies are present among several pedagogical resources that teachers use to present 


\section{State of the literature}

- Analogies are present among several pedagogical resources that teachers use to present scientific concepts. Their use in classrooms and textbooks often takes for granted that analogies are easy to understand and use for students.

- Although some authors have pointed multiple advantages of analogies as pedagogical tools, some others have considered their drawbacks due to the fact that analogies are never based on an exact fit between analogue and target; their use requires considerable guidance and elaboration.

- Some studies have described the use of analogies in regular teaching practice. Studies of this kind are scarce but provide interesting examples of the kind and variety of analogies that teachers 'regularly use in their science classes and their potential as meaning making tools.

\section{Contribution of this paper to the literature}

- Two empirical studies on the use of analogies in primary classrooms were analysed to discuss on their effectiveness as pedagogical resources.

- Results from both studies suggested that the most determinant elements in the effectiveness of the analogy in question were: how it was presented, its context and how much students were involved in mapping the analogical relations.

- These outcomes strongly suggests that research and pedagogical practice should shift from determining the effectiveness of analogy in cognitive transfer, from analogue to target domains, towards the recognition of its role in generating engagement in developing meaningful explanations through verbal interactions among teacher and students.

scientific concepts. Their use in classrooms and textbooks often takes for granted that analogies are easy to understand and use for students. Nevertheless, research suggests that even when analogies are common place in human communication, they are not always as effective in the classroom as might be expected. In this context, the discussion can be centred on two questions:

- How effective can be analogies as teachings aids?

- What circumstances can be related to the effective use of analogies in science teaching?

In this paper there is a critical overview of the role of analogies in science education and an analysis of two empirical studies about the use of analogies in real primary classroom settings. Finally, I discuss the strengths and limitations of analogies when they are used to promote understanding of scientific ideas.

\section{ANALOGIES IN SCIENCE EDUCATION}

\section{What is meant by analogy in science education?}

Harré (1972) has defined analogy as a relationship between two entities or processes, which allows to make inferences about one of the things, usually about the one we know the least, on the basis of what we know of the other. For Glynn (1991) an analogy is, in a more general way, a process of identifying similarities between different concepts. Glynn's definition is very broad and seems to be applicable to the wide range of devices referred as analogies in educational literature.

Duit (1991) has suggested that even when analogy, model and metaphor are terms related to establishing comparisons and similarities between different domains, some differences among them can be drawn. He argues that models, like analogies, have to do with the structural mapping of different domains, but they particularly represent parts of structures of target domains as a whole (e.g. the camera as a model of the human eye). Models may, therefore, provide analogies. It is the analogical relation that makes a model, a model. An analogy, he says, explicitly compares the structures of two domains; it indicates identity of parts, structures or functions (e.g. "flowing water in the water circuit is like electric current in the electric circuit"). Metaphor compares implicitly, highlighting features or relational qualities that do not coincide in two domains and taken literally is absurd (e.g. calling a teacher 'the captain of the ship').

Duit and Glynn (1996) have called metaphors, allegories, fables and parables relatives of analogies as they have in common the establishment of analogical relations. The frequent use of the term analogy to refer to simple comparisons, models or metaphors prevails in educational literature, scientific and technical context.

\section{Perspectives on the use of analogies}

It is frequently argued that analogies may be valuable tools in teaching and learning scientific concepts. Duit (1991), 'deliberately taking a constructivist position', asserts that analogies are powerful tools to facilitate learners' construction process on the grounds of concepts that are already available. He also points out the significant explanatory and heuristic functions of analogies in the development of science and asserts that they must be considered as an essential aspect of science instruction.

Arnold and Millar (1996) have also made the point that analogies can support understanding by abstracting the important ideas from the mass of new information, making clear the system boundaries and introducing the appropriate language in which to frame a scientific explanation. The power of analogical relationships is 
said to be based in their potential to comprise an entire set of associative relationships between features of the concepts that are compared (Glynn, 1991).

The key role that analogies can play has been analysed by Venville \& Treagust (1996) using classroom evidence. According to their findings, analogy can act as:

A sense maker to transfer the basic structure from a familiar

domain to an unfamiliar one in order to establish

intelligibility of the new science material being taught

A memory aid to help students recall a concept which is difficult to remember

A transformer which facilitates the change in the mind of the learner from 'matter' to 'processes'

A motivator to enhance the self-efficacy of students and give them confidence in their ability to learn the science content

Despite the apparent benefits that analogies can provide as pedagogical tools, there are also warnings in the sense that they 'may give birth to as many monsters as healthy babies' (Kircher, 1989; quoted in Duit, 1991). Uncritical use of analogies may generate misunderstanding, and this seems to be especially so when unshared attributes are treated as valid or when the learners are unfamiliar with the analogy (Harrison \& Treagust, 1993).

An analogy can be used to explain correctly and even predict some aspects of the target concept. At some point, however, every analogy "breaks down" as there are always a number of similarities and crucial dissimilarities. It is precisely at that point when miscomprehension and misdirection can begin (Glynn, 1991). For this reason, Duit and Glynn (1996) have said that analogies are 'double-edged swords'.

An equilibrated position about the use of analogies seem to be sensible and it is well summarised by Duit (1991). He writes that the advantages of analogies follow from the fact that they open new perspectives; they may provide visualisation and facilitate understanding of the abstract by pointing out similarities; they may provoke students' interest and motivate them; and they encourage the teacher to take students' initial ideas into consideration and subsequently this may reveal alternative conceptions. However, he also considers possible disadvantages due to the fact that analogies are never based on an exact fit between analogue and target; their use requires considerable guidance and elaboration, and if students hold 'misconceptions' in the analogue domain, they will probably transfer them into the target domain.

A careful examination of all the aspects of an analogy seems to be a pre-requisite to using it effectively. Harrison \& Treagust (1993) have suggested that three elements are essential for the appropriate use of analogies: the need to consider the students' background so that the chosen analogy is familiar to as many students as possible, the shared attributes should be precisely identified by the teacher and the students, and where the analogy breaks down should be explicitly identified.

Other authors, as a result of analysis and reflection about the way in which analogies are used in textbooks and classrooms have produced some models or teaching approaches for effective use of analogies in instruction. The 'bridging with analogies' approach of Clement et. al. (1989) and the TWA (Teaching with Analogies) Model of Glynn (1991) are some examples. Glynn proposes an abstract representation of analogy (see Figure 1). He calls the familiar concept the analogue and the unfamiliar one, the target, and considers that both can have a superordinate concept.

The TWA model arose from an analysis of science textbooks in which key operations performed by the authors were identified when using effective analogies from the standpoint of instructional design. The TWA model contains the following operations:

1. Introduction of target concept

\section{SUPERORDINATE CONCEPT}

$\begin{array}{ccc} & & \\ \text { ANALOGUE } & \text { compared with } & \text { TARGET } \\ \text { feature } & \text { " } & \text { feature } \\ 1 & \text { " } & 1 \\ 2 & \text { " } & 2 \\ 3 & \text { " } & 3 \\ \text { n } & & n\end{array}$

Figure 1. Abstract representation of an analogy (Glynn, 1991) 
2. Recall of analogue concept

3. Identification of relevant features of target and analogue

4. Mapping of similarities

5. Drawing conclusions about target

6. Indication of where the analogy breaks down

Glynn suggests that this model can serve as a guide for teachers and authors of science textbooks for using an analogy to explain a science concept. It can help, he said, to interpret, analyse, extend or create an instructional analogy. This model can be potentially useful, even when only provides a proposal of steps to be followed and it seems to consider the analogy in isolation and not as a part of a teaching sequence. However the proposed steps can be useful to focus on key aspects of using analogies with instructional purposes.

Duit (1991) has commented that in the steps proposed in the TWA model, it is necessary to make sure that students really see the similarities the teacher has in mind. The representation of the analogy and the TWA are considered in next sections when analysing the studies in primary classroom settings.

\section{The use of analogies in regular teaching practice}

Some studies have described the use of analogies in regular teaching practice. Studies of this kind are scarce but provide interesting examples of the kind and variety of analogies that teachers 'regularly use in their science classes (see Table 1).
According to these studies, the presentation of analogies is mainly through verbal descriptions (varying from the simple mention of a similarity between two domains to an elaborated description or a story) and physical entities (e. g. overhead transparencies, models, demonstrations with different materials, children's representations). Their use varies from the simple comparisons with no further discussion, to enriched, elaborated and clear comparisons in which students are involved (Treagust et. al., 1992, Sizmur \& Ashby, 1997). It is clear that not all the points of similarity and dissimilarity are usually set out explicitly by teachers and neither it is stated what every entity in the analogue represents.

In the study by Treagust et. al. (1992), teachers seldom used analogies in their teaching and tended to use them in an unelaborated manner. In the forty lessons observed, only six of them were detected. Teachers also appeared to presuppose that students were familiar with the analogue domain and would understand the analogies without much guidance.

It has also been evident that the usefulness of analogy for students may depend on several factors as the difficulty of the science concept, the previous knowledge of students and the teaching style of the teacher (Venville \& Treagust, 1996). How the analogy is presented, its contexts, and how much students are involved in mapping the analogical relations seem to be more determinant than the analogy itself. This strongly coincides with the position that research and pedagogical practice should shift from determining the

Table 1. Examples of analogies that teachers use in regular practice

\begin{tabular}{|c|c|c|c|}
\hline Study & Target & Analogue & Students' age \\
\hline $\begin{array}{l}\text { Treagust et. al. } \\
(1992)\end{array}$ & $\begin{array}{l}\text { Function of enzymes } \\
\text { Genes and chromosomes } \\
\text { Electricity flow } \\
\text { Electric field }\end{array}$ & $\begin{array}{l}\text { Lock and key model } \\
\text { Pop-beads } \\
\text { Water flowing in pipes } \\
\text { Gravitational field }\end{array}$ & $14-17$ \\
\hline Dagher (1995) & $\begin{array}{l}\text { Selective vision of some birds } \\
\text { Responsibility in lab activities } \\
\text { Attraction between electrons and } \\
\text { protons } \\
\text { Scientists use of evidence } \\
\text { AIDS virus in body } \\
\text { Spinal cord }\end{array}$ & $\begin{array}{l}\text { Colour-blind people } \\
\text { Driver's license } \\
\text { Boys and girls } \\
\text { Police } \\
\text { Alien } \\
\text { Telephone cable }\end{array}$ & $12-13$ \\
\hline $\begin{array}{l}\text { Venville \& Treagust } \\
\text { (1996) }\end{array}$ & $\begin{array}{l}\text { Classification of living beings } \\
\text { Homeostasis in humans } \\
\text { Cell membranes } \\
\text { The heart }\end{array}$ & $\begin{array}{l}\text { Supermarket sorting and display } \\
\text { Car cool system } \\
\text { Fluid mosaic } \\
\text { Buckets and pumps }\end{array}$ & $12-15$ \\
\hline $\begin{array}{l}\text { Sizmur \& Ashby } \\
\text { (1997) }\end{array}$ & $\begin{array}{l}\text { Human circulatory system } \\
\text { Human circulatory system } \\
\text { Sun } \\
\text { Movement of stars, planets and } \\
\text { satellites }\end{array}$ & $\begin{array}{l}\text { Other systems (e.g. hi-fi, railway) } \\
\text { Plant circulatory system } \\
\text { Desk lamp } \\
\text { Children's dancing }\end{array}$ & $10-11$ \\
\hline Blake, (2004) & Cycle of rock formation & Aluminium can recycling & $9-11$ \\
\hline
\end{tabular}


effectiveness of analogy in cognitive transfer, from base to target domains, towards the recognition of its role in generating engagement in developing meaningful explanations through discourse (Heywood, 2002). This issue goes along with the emergence of argumentation as a significant goal for teaching and learning science (Erduran et al, 2006).

Studies reveal that the way in which an analogy is built up in the classrooms is often far from simple. Dagher (1995) asserts that teachers' analogies represent windows into their values, concerns, pedagogic content knowledge and skills in engaging their students in learning. Teachers seem to be generally aware of both the benefits and limitations of analogies, however they are not very confident about using them effectively (Venville \& Treagust; 1996). The researchers coincide in the importance that teachers are aware of where the analogies break down and take steps to avoid reinforcing possible misconceptions (Treagust et. al., 1992; Sizmur \& Ashby, 1997).

\section{STUDIES OF ANALOGY USE IN CLASROOM SETTINGS}

Attention is now turned on two studies in which researchers have explored and evaluated the use of analogies as part of a teaching sequence and their learning outcomes in primary classrooms. Several studies related to the use of analogies in teaching and learning science (Clement et. al., 1989; Dagher, 1995, Harrison \& Treagust, 1993; Sizmur \& Ashby, 1997; Treagust et. al., 1992; Venville \& Treagust, 1996) could be considered under the banner of constructivist perspectives. Such perspectives can be considered, in a very broad sense, as the ones that assume that learning is an active construction process and is possible only on the basis of previously acquired knowledge, rather than passive taking and storing of pieces of knowledge.

More particularly, some of them have been conducted with the view of learning as conceptual development or conceptual change (e. g. Treagust et. al., 1992; Venville \& Treagust, 1996; Schwedes \& Dudeck, 1996) which is also the case of the two reviewed here in detail. In their seminal paper on conceptual change, Posner et. al. (1982) described analogies and metaphors as a feature of the conceptual ecology which can serve to make concepts intelligible.

\section{Study 1: Electric current and the 'string circuit' analogy}

The study of Asoko (1996) can be considered in a social constructivist perspective which recognises that science learning involves 'being initiated into the ideas and practices of the scientific community', a view that is widely discussed in Driver et. al. (1994). This study is an interesting case in which researcher and teacher work together to develop and evaluate a teaching sequence.

The 'string circuit' analogy was used to support the development of children's understanding of energy transfer and current flow in simple electrical circuits. The study intended to investigate whether this analogy made sense to primary school children, the learning outcomes which resulted from its use as part of a teaching sequence and the teacher action which affected children's progress in developing their understanding. It was conducted in with students aged 8-9 in a primary school in northern England. The researcher was present during the teaching and acted as an observer who made no teaching input but provided feedback and suggestions to the teacher.

The analogy used is one that in the experience of Asoko has been useful for trainee teachers to develop their own understanding of electric circuits. It consists on a representation in which participants stand in a circle and loosely support with their hand a continuous string loop that a person makes circulate. Following the representation of an analogy proposed by Glynn (1991) we can present it as in Figure 2.

superordinate concept

CIRCUIT

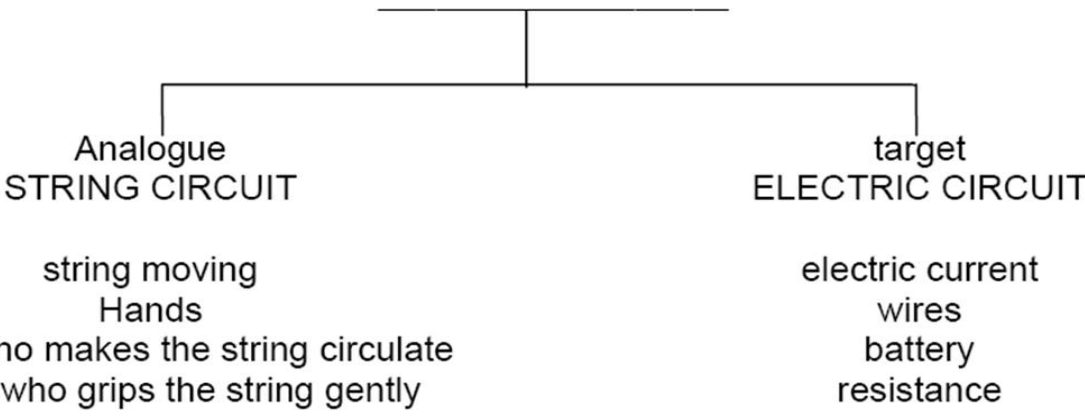

Figure 2. Representation of the 'string circuit' analogy 
This analogy corresponds more to what Duit (1991) calls a model, as it has to do with the structural mapping of different domains and allows establishing analogical relations. The relations in this case are structural and functional and can be built with the help of concrete, physical entities that facilitates the visualisation of abstract elements of the target domain. Remarkable advantages of the analogy were that it needed no complicated equipment, made no assumptions about children's familiarity with it, and students were directly involved in its representation.

The teaching sequence considered an initial stage of three sessions in which students' ideas about electricity and its effects were explored and students had the chance to observe and draw a light bulb. They also tried, discussed and recorded different arrangements to make a bulb light using a battery and a piece of wire. The exploration of initial ideas suggested that some students considered that 'energy', 'electricity' or 'power' left the battery from both ends, met the bulb and caused it to light. Others had some notion of a circular movement.

The analogy was introduced and discussed in session 4. The teacher set up the 'string circuit' involving all the children and himself as the battery. Students were encouraged to describe what was happening and the teacher explained the utility of the analogy in terms of its help 'to understand what might be happening where we can't see' (inside the wires). At this point the teacher emphasised main ideas concerning the provision of energy by the battery, that energy makes the bulb light, that energy is carried by current and that current travels around the circuit and back to the battery. Later, in the same fourth session, students also made circuits and related them to the analogy. Fifth session included the exploration of different combination of circuit components. Finally, construction of circuits to investigate conductors and insulators and a summary of main ideas were considered in session 6.

Interestingly, all the key operations that Glynn (1991) consider in his model for using analogies seem to be present in this teaching sequence except the last one, the indication of where the analogy breaks down.

Evidence of the effectiveness of the teaching sequence was provided by the results obtained from a questionnaire applied a week after the end of the teaching and reapplied six months later. The questionnaire evaluated students' ability to recognise the features of a complete circuit and their explanations of what happen in the circuits to make the bulb light. The responses to the questionnaire revealed that most of the students $(74-100 \%)$ succeed in identifying whether the bulb would or would not light in four of five arrangements presented. Even when some students gave non-specific responses, the majority could correctly and unambiguously describe appropriate alteration to the circuits where the bulb would not light. These results were similar in both test applications. Direct application of the analogy by the students was not explored in the questionnaire.

Students accounts of what was happening to make the bulb light ranged from simple descriptions of the circuit to explanations in terms of current or energy.

Students' responses to the questions that specifically asked to use the words energy and current revealed that ideas introduced during teaching were used correctly by most of the children.

Commenting on how the whole teaching strategy worked, Asoko indicates that students grasped the idea of circular flow but apparently had not differentiated between current and energy. It is remarkable that such differentiation is difficult to make in the 'string analogy'. The inconsistent use by the teacher of the term 'current' seemed also to be related to this aspect. She also points out that children appeared able to understand the analogy and its relationship to the circuits they constructed, but not unexpectedly, they need considerable help from the teacher to use the analogy to explain their observations. However, most of children seemed to have developed elements of a scientific understanding about the behaviour of electricity in simple circuits.

The most relevant conclusions of this study point that the analogy was useful to make scientific ideas about electricity accessible to young children but underline that children will need time, opportunity and support to use the analogy to guide and structure their thinking. The role of the teacher in the process seems to be crucial. Asoko also remarks the importance of selecting an appropriate analogy to the experience of students and to the teaching aims; and recognising that simply presenting an analogy as part of a teaching sequence do not, by itself, produce understanding or meaning making. Teachers, she says, need to be aware of the strengths and weaknesses of an analogy, consider at what point it could most usefully be presented, and focus students' attention on salient features.

\section{Study 2: Photosynthesis and the 'making a cake' analogy}

Mason's (1994) study was inserted in a research project to analyse analogical reasoning processes in learning science topics in the primary classroom environment. She adheres to the idea of meaningful learning as 'a generative process in which students construct relations among experiences, concepts and higher order schemata and principles' (p. 267). This is a 'personal' constructivist perspective. The study assumes that in conceptual change, cognitive and meta-cognitive abilities are involved and set out that metacognition is intended as the awareness or ability to reflect on what and when, how and why, one knows. 
Underlining the importance of helping students become more aware of their own learning processes and to take responsibility and control on them when promoting conceptual change, is a position that coincides with this study and the incorporation that Hewson et al. (1996) have made of meta-cognitive aspects among what they call 'guidelines for teaching for conceptual change'.

The aim of the study was to explore the relation between the students' use of analogy in learning science, their level of understanding of the analogy itself and the "meta-cognitive awareness" of their own understanding and the instructional purpose of the analogy. It involved a class of fifth grade in a primary public school in northern Italy that had previously a learning experience with the analogy between the human circulatory system and the mail delivery system. Despite the whole class being involved in the learning experience, the reported results include only fifteen children. In this study the researcher took the place of the teacher and performed the teaching sequence considering ten sessions.

Children's prior knowledge about plants and their nutrition was explored before implementing the teaching sequence and revealed that students admitted that plants were living beings and needed some elements to survive (water, minerals, light, air, soil). A common idea was that plants get their food from the soil through the roots which absorb water and minerals. They had diverse ideas about the function of leaves: capturing the warmth of the sun, breathing, protecting the plant and releasing oxygen. Other ideas involve the roots, the bark and flowers in respiration. Children held a widespread confusion between photosynthesis and respiration in plants and often established similarities between animal nutrition and plant nutrition.

The first sessions dealt with topics related to plants as living beings. Breathing and transpiration were studied and related experiments were conducted in the classroom. Students were also taught about the importance of light and air for plants and the presence of chlorophyll in leaves. The analogy was introduced in the sixth session by the researcher. She presented it only through verbal description, pointing that there were some correspondences between photosynthesis and making a cake. Following Glynn, the analogy used can be represented as in Figure 3.

Students were engaged then in understanding the ways in which new concepts were similar to the familiar source, by detecting the relations between the two processes. They stated the ingredients to be mixed to make a cake and mapped the relations onto the target. Not unexpectedly, students could only identify water and minerals as raw materials in photosynthesis. The help of the researcher was necessary to consider carbon dioxide. The similarity between oven heat and sunlight was easily detected. Students needed considerable help to identify the end product in photosynthesis.

At this point, researcher introduced the function of chlorophyll as a "catalyst" to change carbon dioxide and water into sugar and oxygen. The absence of a catalyst in making a cake was pointed as dissimilarity between the compared processes, but students also identified other differences. In this way, where the analogy breaks down was made explicit.

The analogical relations were summarised at the end of the session. No details are considered in the article about the sessions after the introduction of the analogy. In this case, all the steps in Glynn's model for the use of analogies seemed to take place in the sixth session.

Questionnaires, interviews, and texts written by students were used to evaluate: a) the conceptual understanding of the topic, b) the understanding of the analogy, and c) their 'meta-cognitive' awareness of the instructional purpose of the analogy. Results showed a high positive correlation among these three factors.

It is worth highlighting some details about the understanding of the analogy. This aspect was ranked at five levels considering progression from the understanding of isolated similarities (level 1) to the understanding of the relational structure and the

superordinate concept

TRANSFORMATION PROCESS

(from raw materials to end products)
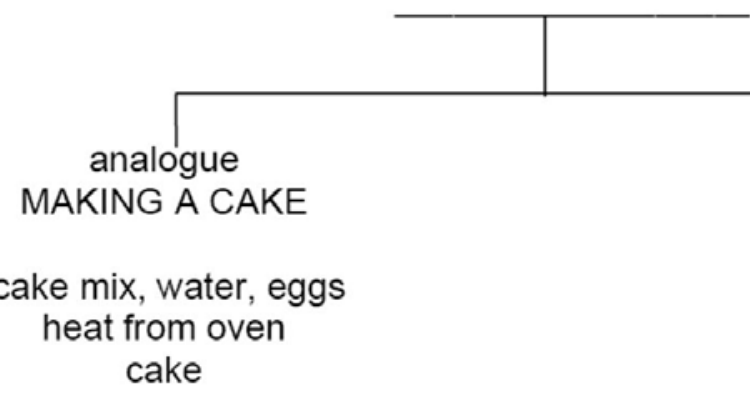
recognition of where the analogy breaks down (level 5). Most of the students reached levels $3(20 \%), 4(20 \%)$ or $5(33.3 \%)$. On this basis, Mason considers that they elaborated the analogy in a way which allowed them to understand the general principle of change process made by plants.

However she comments that children attained different levels when applying the relations detected in the process of making a cake to the process of photosynthesis. Regarding what she calls the low level, there was evidence that some children confused the raw and end products in the mapping processes between source and target, for example in the following text of a child:

A cake is made of sugars, we need sugars to make a cake and also plants need sugars, and to mix these substances oven heat and water are necessary.

Children with intermediate and higher level of understanding the analogy were able to express in their texts the idea of end production from raw materials, to recognise the super-ordinate principle (transformation process) and where the analogy breaks down. The concept of raw material as something breathable was complicated. Some children had difficulties in understanding that raw materials, a liquid and a gas, through a chemical reaction could be transformed in energy-containing food. After instruction, three children reinforced their initial idea that plants, by absorbing carbon dioxide and releasing oxygen during the day, do not breathe in the same way as human beings but rather in the opposite way.

Concerning 'meta-cognitive awareness", some students simply admitted that the analogy was useful, others could not recognise if the analogy helped them to change their initial ideas. Some others could clearly express which ideas about plant nutrition they had changed by using of analogy.

From the results of this study it is clear that when the analogy is introduced is not automatically well understood and interacts with the alternative conceptions on the target. Mason asserts that the high correlation between the understanding of the analogy and the conceptual understanding of the topic demonstrates that the analogy provides "assimilative schemata" for incoming information and structural basis for restructuring existing knowledge, as well.

The correlation between conceptual understanding and metaconceptual awareness suggests a strong interaction of these elements, however, as Mason mentions; no causal relations can be drawn. The outcomes of this study support the idea that the introduction of analogies can be useful to stimulate conceptual understanding but it is not a panacea. Consideration to students' prior knowledge, their understanding of the analogy itself and awareness about its use for teaching purposes seems to be crucial.

\section{DISCUSSION}

Both studies analysed here exemplify interesting cases in which particular analogies were used to promote understanding of two traditional concepts considered in primary science. They provide hints about the use of analogies with young children, their potential and the aspects that need particularly attention.

How effective were the analogies? Even when for a fair discussion of 'effectiveness' it would be necessary to compare the outcome of using an analogy with other teaching approaches, some comments can be made. The evaluation of the learning outcomes suggests they were good and adequate, but it is clear that the analogies did not work well for all students. Glynn (1991) has proposed that a good analogy is powerful, considering that its power increases as the number of features compared increases, and if the features are directly relevant to specific instructional goals. Both analogies allowed establishing several comparisons. In the case of the 'string circuit', it seemed to be particularly useful to reinforce the idea of circular and continuous flow of electric current. The 'baking a cake' analogy served to emphasise the idea of a transformation process. Following the criteria proposed by Glynn, both analogies can be considered good as they clearly were not unfamiliar or unintelligible to students and helped to identify and map the important features to be compared. Performing the key operations proposed in Glynn's (1991) TWA model, as in the study of Mason, is important but it is not necessarily a guarantee of success. To consolidate understanding of the scientific concept, the presentation of the analogy seems not to be enough. Further opportunities to understand, discuss and apply the new ideas should complement the use of analogies.

In these studies we can see two ways of presenting the analogy: verbal description and by means of a physical representation. The way in which an analogy is presented is not irrelevant and different possibilities of presenting the same analogy would be interesting to explore. The opportunity for students to map the analogical relations by themselves instead of being told about them was present in both studies and it was clearly coupled with considerable guidance from the teacher.

A remarkable merit of Mason's study was to give particular attention on how well the analogy was understood and to make the point that students need to perceive the instructional purpose of the analogy to better understand it and use it. However, even when Mason's study provides evidence connecting metacognitive aspects (awareness of the aim of the analogy and its help to modify previous ideas, in this case), conceptual understanding and analogy understanding, Dagher (1995) suggests that other meta-cognitive 
aspects related to analogies need further exploration, as students' reflection about advantages and disadvantages of analogy and their own evaluation of comparisons.

Asoko focused more in the conceptual understanding outcomes than in the analogy itself. The analogy was considered one more element in the teaching sequence but not the main one, as it seems to be in Mason's approach. The use of analogy in Asoko's study was clearly only a resource to make some ideas accessible to children and it was integrated in a carefully planned sequence in which the collaboration of a researcher and a teacher seem to produce good results.

Sometimes is simply taken for granted that analogies are understood and used by students without any further guidance. In order to increase effectiveness in the use of analogies, teachers need to have in mind their limitations and be aware that analogies are a very powerful way can communicate certain messages and conveniently ignore others. Adúriz-Bravo et al. (2005) have suggested that analogies need to be considered among the strategies that teachers need to develop in order to incorporate school scientific argumentation as a teaching skill. They need to be prepared to guide students in mapping relevant features and identifying the points where the analogy breaks down in order to avoid misunderstanding, inappropriate comparisons or oversimplification of the new concepts. The level at which the analogy is understood seems to be another important aspect to be considered. The time, support and opportunities that teachers give to students to make sense of the analogy and use it to structure their thinking (Asoko, 1996) are undoubtedly factors that support meaning making. The importance of selecting an appropriate analogy to the experience of students and to the teaching aims pointed by Asoko (1996) and the consideration to students' prior knowledge, their understanding of the analogy itself and awareness about its use for teaching purposes that Mason (1994) suggests; are issues applicable in general to the use of analogies in primary education.

\section{FINAL COMMENTS}

The studies with primary students reviewed here suggest that analogies as pedagogical tools have strengths and limitations. Analogies are clearly not a magic resource to promote understanding of scientific concepts but their potential can be capitalised if they are prudently used. Other studies conducted in the context of science teaching in secondary and high school also support this reserved position. For instance in the study of Schwedes \& Dudeck (1996), students seemed to understand the water circuit analogy and had no serious difficulties in using for making inferences in the electric circuit domain. They add that the use of the water analogy leaded to a certain reduction of problems of understanding electric circuits, but the construction of a consistent network of knowledge about water circuits proved to be more difficult than anticipated. Another study by Arnold and Millar (1996) also pointed that half of their students were able, with prompting, to use a water-flow analogy to explain the process of thermal equilibrium. Even when they admit that the analogybased approach is worth pursuing, they warn that students can not be expected to make the connections spontaneously and require congenial assistance and prompting.

Duit (1991), commenting on empirical studies on analogical reasoning, recognises that the results of this kind of studies are somewhat ambiguous. Some of them point that analogy facilitates comprehension and problem solving, but some others have had unsuccessful results when the areas seen as obviously similar by the teacher are viewed as being fundamentally different by students or when the analogue domain is unfamiliar to students. It has also been suggested that analogy use in teaching is likely to be unsuccessful if they are used in a context of a encyclopedic learning environment assuming that they can be well-understood without further guidance and ignoring that inevitably they interact with students previous knowledge (Treagust et. al., 1992). The idea that analogy may be a potential intellectual trap as well as an invaluable intellectual tool (Nagel, 1971) seems to be supported by research findings.

The virtues of analogies seem to be their potential to prepare a source-domain from which structured knowledge can be built up, to support understanding by abstracting the important ideas from the mass of new information and to provoke students' interest. Their limitations concern the assumption made in some cases about the familiarity of the students with the analogue, the chances to establish invalid analogical relations, to oversimplify the target concepts and the considerable guidance that students require to use them.

It is not easy to make generalisations about the effective use of analogies, as their use in teaching different science concepts may interact with the nature and demands of particular topics on students, their previous knowledge and experience, the teacher's style, among other factors. However some salient aspects to have in mind can be drawn:

- Teachers need to plan their use in a way which takes account of their potential and limits and avoid uncritical use of analogies in classrooms.

- A careful identification of the relevant features of the analogy and the points in which it breaks down seems to be a prerequisite to using it effectively.

- Reflection and careful planning on how and when to introduce the analogy, against improvisation, are crucial.

- The analogy selected must be appropriate to the experience of the students and the teaching points to be made (Asoko, 
1996). A careless selection involves the risk of presenting an analogy which points of dissimilarity are even more than the relevant ones.

- Very structured analogy taught without negotiation of meanings may be understood so literally as to become an obstacle for further understanding (Dagher, 1995).

- Opportunities and guidance for students to identify the analogical relations and evaluate their feasibility should be provided. However, how much it is necessary to spell out the mappings between the domains is clearly a matter of judgement (Sizmur \& Ashby, 1997).

- Care needs to be taken to avoid conveying the impression that the analogue is a true description of the target or that all features of target have correspondence in the analogue (e. g. James \& Scharmann, 2007).

- The nature of the analogy, as a mean to support understanding of scientific concepts, may need to be introduced in an accessible level for students.

- The analogies may not be fruitful in isolation, but as part of a teaching sequence that combine different pedagogical resources.

As Asoko (1996) suggests, a well-prepared repertoire of analogies does not exist among primary teachers, but probably its elaboration is worth-pursuing. Criteria concerning effective use of analogies did not seem to be known to many authors of textbooks and teachers (Glynn, 1991, Duit, 1991). The virtues of analogies should not lead to their indiscriminate use but, on the other hand, their limitations should not conduct to abandon them as pedagogical tools. The challenge is to use them in an effective way and capitalise their potential. Among other relevant elements in need to be incorporated to innovative teacher education schemes (Akgul, 2006), pedagogical use of analogies still need to be recognised as part of teaching expertise.

Driver et al. (1994) have suggested that teaching science involves leading students towards conventional science ideas and that teacher's intervention is essential, to make the concepts, symbols and conventions of science available to students. It seems that analogy can play and important role in that task if it is seen as a resource to promote understanding and meaning making but its strengths and limitations are not ignored.

\section{REFERENCES}

Adúriz-Bravo, A., Bonan, L., Galli, L. G., Chion, A. R. and Meinardi, E. (2005) Scientific Argumentation in PreService Biology Teacher Education. Eurasia Journal of Mathematics, Science and Technology Education, 1(1), 76-83.

Akgul, E. M. (2006) Teaching Science In An Inquiry-Based Learning Environment: What It Means For Pre-Service Elementary Science Teachers. Eurasia Journal of Mathematics, Science and Technology Education, 2(1), 71-81.

Arnold, M. \& Millar, R. (1996). Exploring the use of analogy in the teaching of heat, temperature and thermal equilibrium, in G. Welford, J. Osborne, \& P. Scott
(Eds.), Research in Science Education in Europe: Current Issues and Themes. London: Farmer Press.

Asoko, H. (1996). Developing scientific concepts in the primary classroom: Teaching about electric circuits, in G. Welford, J. Osborne, \& P. Scott (Eds.), Research in Science Education in Europe: Current Issues and Themes. London: Farmer Press.

Blake, A. (2004). Helping young children to see what is relevant and why: supporting cognitive change in earth science using analogy. International Journal of Science Education, 26 (15), 1855-1873.

Clement, J.; Brown, D. \& Zietsman, A. (1989). Not all preconceptions are misconceptions: finding 'anchoring conceptions' for grounding instruction on students' intuitions. International Journal of Science Education, 11, 554565.

Dagher, Z. (1995). Analysis of analogies used by science teachers. Journal of Research in Science Teaching, 32 (3), 259270.

Driver, R.; Asoko, H.; Leach, J.; Mortimer, E. \& Scott, P. (1994). Constructing scientific knowledge in the classroom. Educational Researcher, 23 (7), 5-12.

Duit, R. \& Glynn, S. (1996). Mental modelling, in G. Welford, J. Osborne, \& P. Scott (Eds.), Research in Science Education in Europe: Current Issues and Themes. London: Farmer Press.

Duit, R. (1991). The role of analogies and metaphors in learning science. Science Education, 75 (6), 649-672.

Erduran, S., Ardac, D. and Yakmaci-Guzel, B. (2006) Learning To Teach Argumentation: Case Studies Of Pre-Service Secondary Science Teachers. Eurasia Journal of Mathematics, Science and Technology Education, 2(2), 1-14.

Eynseck, H. J. (2000). Intelligence: A New Look. New Jersey: Transaction Publishers.

Glynn, S. (1991). Explaining science concepts: a TeachingWith-Analogies Model, in S. Glynn, R. Yeanny \& B. Britton (Eds.), The Psychology of Learning Science. New Jersey: Erlbaum.

Harré, R. (1972). The philosophies of science: an introductory survey. London: Oxford University Press.

Harrison, A. \& Treagust, D. (1993). Teaching with analogies: A case Study in Grade-10 Optics. Journal of Research in Science Teaching, 30 (10), 1291-1307.

Hewson, P.; Beeth, M.; \& Thorley, R. (1998). Teaching for conceptual change, in B. F. Fraser \& K. G. Tobin (Eds.), International Handbook of Science Education. Great Britain: Kluwer Academic Publishers.

Heywood, D. (2002). The place of analogies in science education. Cambridge Journal of Education, 35, 233-247.

James, M. \& Scharmann, L. (2007). Using analogies to improve the teaching performance of preservice teachers. Journal of Research in Science Teaching, 44 (4), 565585.

Mason, L. (1994). Analogy, metaconceptual awareness and conceptual change: a classroom study. Educational Studies, 20 (2), 267-291.

Nagel, E. (1971). The Structure of Science: Problems in the Logic of Scientific Explanation. London: Routledge.

Schwedes, H. \& Dudeck, W.-G. (1996). Teaching electricity by help of a water analogy: How to cope with the need for conceptual change, in G. Welford, J. Osborne J. \& 
P. Scott (Eds.), Research in Science Education in Europe: Current Issues and Themes. London: Farmer Press.

Sizmur, S. \& Ashby, J. (1997). Introducing scientific concepts to children. Great Britain: National Foundation for Educational Research.

Treagust, D.; Duit, R.; Joslin, P. \& Lindauer, I. (1992). Science teachers' use of analogies: observations from classroom practice, International Journal of Science Education, 14, (4), 413-422.

Venville, G. \& Treagust, D. (1996). The role of analogies in promoting conceptual change in biology. Instructional Science, 24, 295-320.

\section{$\diamond \diamond \diamond$}

